\title{
Expression of thyroid transcription factor- 1 is associated with a basal-like phenotype in breast carcinomas
}

Tor A Klingen ${ }^{1 *}$, Ying Chen ${ }^{1}$, Pål Suhrke ${ }^{1}$, Ingunn M Stefansson ${ }^{3,4}$, Marian D Gundersen ${ }^{2}$ and Lars A Akslen ${ }^{3,4}$

\begin{abstract}
Background: The differential diagnosis between primary and secondary breast cancers might be difficult, especially in poorly differentiated tumors. Thyroid Transcription Factor-1 (TTF-1) has been regarded as a reliable marker for lung or thyroid origin, with only occasional positive staining in other tumors. However, positive cases have recently been reported among primary breast carcinomas.

Methods and results: Here, we analyzed expression of TTF-1 protein (clone SPT24) by immunohistochemical staining of sections from paraffin embedded tumor samples in 247 primary breast cancers from the populationbased Norwegian Breast Cancer Screening Program. Positive staining (weak or strong) was observed in 7 cases $(2,8 \%)$. As novel observations, positivity was demonstrated more frequently in estrogen receptor negative cases $(14,0 \%$ vs. $1,4 \% ; p=0,004)$, highly proliferative tumors ( $8,8 \%$ vs. $1,1 \% ; p=0,008)$, tumors with a basal-like phenotype by showing expression of CK5/6 and/or P-cadherin (11,1\% vs. 1,4\%; $p=0,01)$, and tumors with blood vessel invasion ( $9,7 \%$ vs. 1,9\%; $p=0,04)$. Also, TTF-1 was associated with histological grade 3 tumors compared with grade 1 or 2 tumors $(7,7 \%$ vs. $1,5 \% ; p=0,04)$ as well as lymph node positive cases $(5,2 \%$ vs. $1,8 \% ; p=0,03)$.
\end{abstract}

Conclusions: Our population-based findings indicate that TTF-1 may be positive in approximately $3 \%$ of primary breast cancers, and positivity indicates an association with adverse prognostic factors.

Virtual slides: The virtual slide(s) for this article can be found here: http://www.diagnosticpathology.diagnomx.eu/ vs/8313753509421182

Keywords: Thyroid transcription factor-1, Breast cancer, Basal-like phenotype, Adverse prognostic factors

\section{Introduction}

Thyroid Transcription Factor-1(TTF-1), also known as Nkx2.1 or thyroid-specific enhancer-binding protein, regulates genes in the thyroid, lungs, and diencephalon during embryogenesis [1,2]. Thus, TTF-1 has been regarded as a reliable marker for tumors originating in lung or thyroid tissues. TTF-1 is expressed in $72 \%$ of adenocarcinomas of the lung [2] and can be a useful marker in identifying lung tissue as a primary origin of metastases, for instance to the breast. However, recent studies have demonstrated that this marker might also be positive in some neuroendocrine tumors of different origins as well as in colorectal, gastric, endometrial,

\footnotetext{
* Correspondence: tor.klingen@siv.no

'Department of Pathology, Vestfold Hospital Trust, Tønsberg, Norway

Full list of author information is available at the end of the article
}

endocervical, ovarian, prostatic, renal, and mesothelial tumors [3-6].

Regarding primary breast cancer, some cases with TTF-1 positivity have been reported [7-11] (Table 1). We recently documented a case of breast cancer with positive expression of TTF-1 [9], and we subsequently wanted to establish the frequency of TTF-1 expression in a population-based setting of breast cancer.

\section{Materials and methods}

We carried out immunostaining for TTF-1 on paraffin sections of 247 primary breast cancers selected from the population-based Norwegian Breast Cancer Screening Program. Vestfold County (Eastern Norway, $5 \%$ of the Norwegian population with around 230,000 inhabitants) was included in the Norwegian Breast Cancer Screening 


\begin{tabular}{|c|c|c|c|}
\hline Reference & $\begin{array}{l}\text { TTF-1 } \\
\text { positiv/total }\end{array}$ & Study population & $\begin{array}{l}\text { TTF-1 } \\
\text { clone }\end{array}$ \\
\hline $\begin{array}{l}\text { Ersahin et al., } \\
\text { Int J SurgPathol } 2009\end{array}$ & $1 / 1$ & Case study & $8 G 7 G 3 / 1$ \\
\hline $\begin{array}{l}\text { Christie et al., } \\
\text { Int Clin Exp Pathol } 2010\end{array}$ & $1 / 1$ & Case study & Unknown \\
\hline $\begin{array}{l}\text { Klingen et al., } \\
\text { DiagnPathol } 2010\end{array}$ & $1 / 1$ & Case study & SPT24 \\
\hline $\begin{array}{l}\text { Robens et al., } \\
\text { Am J SurgPathol } 2010\end{array}$ & $13 / 546$ & Unselected & SPT24 \\
\hline $\begin{array}{l}\text { Sakuray et al., } \\
\text { Histopathol } 2011\end{array}$ & $4 / 134$ & Unselected & $8 G 7 G 3 / 1$ \\
\hline Present study & $7 / 247$ & Population-based & SPT24 \\
\hline
\end{tabular}

Program in 2004. A total of 37,977 women participated during the study period from 2004 to 2008; attendance rate was $71 \%$ and $76 \%$ during the first two screening rounds. During the first two rounds, 204 invasive screen-detected cancers were reported, and 46 invasive interval breast cancers following the prevalent and subsequent round were found. Three cases were excluded from this series: one screen-detected cancer had no residual tumor tissue for further investigation; one screen-detected tumor was diagnosed as a malignant phyllodes tumor, and one patient with interval cancer suffered from multiple metastases at the time of diagnosis, and no biopsy or surgery was therefore performed. Thus, a total of 247 invasive carcinomas were available for this population-based study, 202 screen-detected and 45 interval cancers.

One representative paraffin embedded block from each surgical specimen, including tumor tissue with adjacent peritumoral tissue, was selected for immunohistochemical staining with TTF-1. In 8 cases, preoperative tumour biopsies were selected for investigation because tumor tissue in surgical specimens was too scanty after neoadjuvant treatment for locally advanced breast cancers (6 cases) or routine pathology investigation ( 2 cases).

Immunohistochemical analyses were performed by routine methods on 4-5 $\mu$ m-thick, formalin fixed, paraffinembedded tissue sections. Briefly, after the slides were dried for 20-60 minutes in a $60^{\circ} \mathrm{C}$ oven, they were placed on the Ventana Benchmark automated immunostainer (Ventana Medical Systems, Tucson, AZ) and dewaxed. Heat-induced epitope retrieval was performed with Ventana`s CC1 retrieval solution for 30 minutes at $95^{\circ} \mathrm{C}$ to $100^{\circ} \mathrm{C}$. Primary antibody Thyroid transcription factor-1 (TTF-1), clone SPT24 (Novocastra/Leica) at a 1:100 dilution, mouse monoclonal antibody, was applied to the sections at $37^{\circ} \mathrm{C}$ for 32 minutes. Presence of the antigen was visualized by using the Ultra View DAB detection kit (Ventana).

TTF-1 positive cases were evaluated for intensity of nuclear expression and expression area. A staining index (values 0-9), obtained as a product of staining intensity (0-3) and proportion of immunopositive tumor cells $(\leq 10 \%=1,10-50 \%=2,>50 \%=3)$, was calculated as previously published [12]. Staining index $\geq 6$ was considered to represent strong TTF-1 expression and a staining index $<6$ was considered a weak TTF-1 expression. Staining was recorded independently by three observers (TK, YC and PS). In cases recorded with different observer evaluation, consensus was obtained after discussion between all three observers. TTF-1 positive cases were also evaluated by Anti-Thyroglobulin staining (clone $2 \mathrm{H} 11+6 \mathrm{E} 1$, Roche).

The cases were divided into two groups according to tumor size $\leq 2 \mathrm{~cm}$ or $>2 \mathrm{~cm}$. Histological grade was recorded according to the Nottingham criteria [13]. Nodal status was reported as negative for lymph nodes without tumor or positive for one or more lymph nodes with tumor spread. Tumor cells invading lymphatic or blood vessels were examined on sections using D2-40 and CD31 as previously described [14]. Briefly, lymphatic vessel invasion (LVI) was recorded if tumor tissue was located within more than one D2-40 positive vessel structure, and blood vessel invasion (BVI) was reported when tumor cells were detected in one or more CD31 positive and D2-40 negative vessels. Methods and evaluation for Cytokeratin 5/6, P-cadherin, Ki67, estrogen receptor (ER), progesterone receptor (PR) and HER2 have been described previously [15].

Data were analyzed using the Fisher`s exact test $(2 \times 2$ contingency table). P-values of 0,05 or less were considered significant.

The study was approved by the Regional Committee for Medical Research Ethics and protocols followed the guidelines by the Helsinki Declaration.

\section{Results}

Among 247 primary breast cancer specimens in this study, 201 (81\%) were invasive ductal carcinomas, 26 (11\%) were invasive lobular carcinomas and the remaining 20 cases (8\%) consisted of a variety of other types of breast carcinomas. 73 cases (30\%) were grade 1, $122(49 \%)$ grade 2 and $52(21 \%)$ grade 3 . We found 189 cases $(77 \%) \leq 2 \mathrm{~cm}$ and 58 cases $(23 \%)>2 \mathrm{~cm}$. The median tumor diameter was $14 \mathrm{~mm}$ in the screening group and $15 \mathrm{~mm}$ in the interval group. 77 cases (31\%) had metastases to one or more lymph nodes. 218 cases $(88 \%)$ were estrogen receptor (ER) positive (by $10 \%$ cut-off value of stained cells); 157 cases (64\%) were progesterone receptor positive. HER2 was score $3+$ in $21(8.5 \%)$ of the cases; score $2+$ was observed in 20 cases (8\%), including 2 with ISH amplification. In 
total, 23 cases were considered HER2 positive (9,3\%), representing $15(7,4 \%)$ of the screen-detected cancers and $8(17,8 \%)$ of the interval tumors.

TTF-1 (clone SPT24) expression was seen in 7 of 247 cases $(2,8 \%)$ in this material (Table 2). Positive staining was shown in 6 surgical specimens and in one preoperative core needle biopsy (Figure 1). Three cases had a high TTF- 1 expression with a staining index of 9 (2 cases), and 6 ( 1 case), while 4 cases had a low TTF-1 expression with a staining index of 3 ( 1 case) and 2 (3 cases). There were 6 surgical specimens with carcinoma in situ in the periphery of invasive tumors, and 3 of these cases (\#2, \#4, \#6) had TTF-1 expression in the carcinoma in situ component. Among the positive cases were six invasive ductal carcinomas and one case of invasive lobular carcinoma (\#6). Follow-up time after tumor diagnosis for TTF-1 positive cases varied from 29-61 months, and one patient (\#1) died from breast cancer. Mean distance from tumors to skin was $27 \mathrm{~mm}$ for TTF-1 positive cases. All 7 TTF-1 positive cases were negative for Anti-Thyroglobulin.

TTF-1 positivity was significantly more frequent with ER negative cases ( $14 \%$ vs. $1,4 \% ; \mathrm{p}=0,004)$, Ki-67 staining by upper quartile $(8,8 \%$ vs. $1,1 \%$; $p=0,008)$, with CK $5 / 6$ or P-cadherin positive cases $(11,1 \%$ vs. $1,4 \% ; \mathrm{p}=0,01)$, with lymph node positive cancers $(5,2 \%$ vs. $1,8 \% ; \mathrm{p}=0,03)$, with histological grade 3 tumors compared with grade 1 or 2 tumors $(7,7 \%$ vs. $1,5 \% ; \mathrm{p}=0,04)$, and with BVI positive cases $(9,7 \%$ vs. $1,9 \%$; $p=0,04)$.

TTF-1 positive tumors tended to be more frequent (although not significant) in interval cancers compared with screening-detected cancers $(6,7 \%$ vs. $2,0 \% ; P=0,12)$, in PR negative tumors compared with PR positive tumors ( $4,4 \%$ vs. $1,9 \%$; $\mathrm{p}=0,26)$, in HER2 positive tumors compared to HER2 negative $(4,8 \%$ vs. $2,7 \% ; \mathrm{P}=0,47)$ and in LVI positive cancers $(4,8 \%$ vs. $2,2 \% ; \mathrm{p}=0,37)$ compared to LVI negative tumors.

\section{Discussion}

In this population-based study, TTF-1 expression was found in 2,8\% of the cases, almost the same frequency $(2,4 \%)$ as Robens et al. [7]. Both studies used the SPT24 clone, but in the study by Robens a different autostainer (DAKO) was used on an unselected material with more biopsies than surgical specimens. Sakuray et al. [8] found 4/134 (3,0\%) cases with positivity for TTF-1 (clone $8 \mathrm{G} 7 \mathrm{G} 3 / 1$ ) in a study using tissue microarrays. All these three studies demonstrated similar frequencies of TTF-1 positivity $(2-3 \%)$ despite some differences in clones and technical conditions.

There are two commercially available clones for monoclonal TTF-1 antibodies in immunohistological use; SPT24 and 8G7G3/1. SPT24 has been suggested to be more specific but less sensitive than 8G7G3/1 [16]. Reviewing previous literature indicates that TTF-1 positive breast cancer has been demonstrated with both clones (Table 1). Matoso et al. [17] found the same sensitivity for SPT24 and 8G7G3/1 in non-pulmonary tumors, under the same technical conditions for antigen retrieval and detection system. However, the SPT24 clone has a stronger nuclear staining and less non-specific cytoplasmic staining than $8 \mathrm{G} 7 \mathrm{G} 3 / 1$ [18]. This clone is recommended by the Nordic Immunohistochemical Quality Control (NordiQC) [19].

Both Robens et al. and our present study demonstrated a significantly higher frequency of TTF- 1 positivity in histological grade 3 tumors. As novel observations, we here find significantly more TTF-1 positive tumors with increased tumor cell proliferation (Ki67), a basal like phenotype (CK5/6 and/or P-cadherin expression), lymph node metastasis, ER negativity, and blood vessel invasion. These findings suggest an association between adverse prognostic factors and TTF-1 positivity in a small subgroup of breast cancers.

In 2000, Perou and co-workers indentified five molecular subgroups of breast cancers (luminal A, luminal B, normal breast-like, Her2 positive or basal-like) by use of cDNA microarray and un-supervised cluster analysis [20], and several studies have since addressed the immunohistochemical surrogates to these subgroups [21]. The basal-like subgroup has variable expressions of high molecular-weight "basal" cytokeratins like CK5/6, CK14, CK17, myoepithelial markers (smooth muscle actin and p63), CD117, P-cadherin and EGFR [22]. Single markers like CK5/6 and P-cadherin have been used previously [23] and in the present study to define this subgroup. Basal-like tumors are often hormone receptor low or negative and Her2 negative (triple negative). Others have used more strict criteria with a "core basal profile": ER negative, Her2 negative and CK5/6 and/or EGFR positive to define these tumors [24]. Morphologically, basal-like breast carcinomas are characterized by high histological grade, increased mitotic counts, marked nuclear pleomorphism, the presence of necrotic areas, pushing borders, and often marked lymphocytic infiltration [21]. A morphology with such basal-like features is demonstrated in one of our TTF-1 positive cases (Figure 2).

Secondary tumors in the breast are uncommon, with a reported frequency of 0,4-2\% [25-27]. Studies [25,26,28] have previously shown that pulmonary carcinoma, malignant melanoma and lymphoma are the three most common secondary tumors. It could be argued that some of our TTF-1 positive cases represent metastases from lung cancer, but we regard this possibility as unlikely. First, six of our cases have carcinoma in situ in the periphery of the invasive tumor (except case \#7). Second, in none of the patients was the tumor close to the skin, as is typical for metastases [19]. One patient (case \#5) had a partially rounded mass located $8 \mathrm{~mm}$ from the skin; however, 
Table 2 Clinico-pathological and radiological characteristics of patients with TTF-1 positive primary breast cancers

\begin{tabular}{|c|c|c|c|c|c|c|c|c|c|c|c|c|c|c|c|}
\hline $\begin{array}{l}\text { Patient } \\
\text { number }\end{array}$ & $\begin{array}{l}\text { Sample } \\
\text { type }\end{array}$ & $\begin{array}{l}\text { TTF-1 } \\
\text { expression } \\
\text { (staining index) }\end{array}$ & $\begin{array}{l}\text { Tumor } \\
\text { diameter } \\
(\mathrm{mm})\end{array}$ & Grade & $\begin{array}{l}\text { Tumor- } \\
\text { positive } \\
\text { lymph-nodes }\end{array}$ & ER & PR & Her2 & $\begin{array}{l}\text { CK 5/6 } \\
\text { and/or } \\
\text { P-cadherin }\end{array}$ & $\begin{array}{l}\mathrm{Ki} \\
67 \\
(\%)\end{array}$ & $\begin{array}{l}\text { Mode of } \\
\text { presentation }\end{array}$ & $\begin{array}{l}\text { Mammo- } \\
\text { graphy } \\
\text { findings }\end{array}$ & $\begin{array}{l}\text { Distance } \\
\text { from skin } \\
(\mathrm{mm})\end{array}$ & $\begin{array}{l}\text { Follow-up time after } \\
\text { tumor diagnosis } \\
\text { (months) }\end{array}$ & Status \\
\hline 1 & SS & Weak (2) & 27 & 3 & $1 / 12$ & - & - & + & + & 50,5 & Screening & Stellate opacity & 47 & 29 & $\overline{D E A D}$ \\
\hline 2 & SS & Strong (9) & 15 & 1 & $0 / 3$ & + & + & - & - & 25,4 & Interval & $\begin{array}{l}\text { Irregular } \\
\text { microlobulated } \\
\text { density }\end{array}$ & 36 & 61 & AW \\
\hline 3 & SS & Weak (3) & 22 & 3 & $1 / 21$ & - & - & - & + & 41,2 & Interval & Diffuse density & 30 & 38 & AW \\
\hline 4 & SS & Weak (2) & 9 & 2 & $1 / 11$ & + & + & - & - & 14,5 & Screening & $\begin{array}{l}\text { Irregular } \\
\text { partially } \\
\text { rounded mass }\end{array}$ & 8 & 60 & AW \\
\hline 5 & SS & Weak (2) & 21 & 3 & $1 / 14$ & - & - & - & + & 41,2 & Screening & Irregular density & 18 & 49 & AW \\
\hline 6 & SS & Strong (9) & 17 & 2 & $1 / 8$ & + & + & - & - & 22,9 & Screening & Irregular density & 33 & 54 & AW \\
\hline 7 & CNB & Strong (6) & 70 & 3 & $0 / 1$ & + & - & - & + & 55,4 & Interval & $\begin{array}{l}\text { Lobulated mass } \\
\text { density }\end{array}$ & 16 & 60 & AW \\
\hline
\end{tabular}

$S S$, Surgical specimen; $C N B$, Core needle biopsy; ER, Estrogen receptor; $P R$, Progesterone receptor; $D E A D$, Dead of disease; $A W$, Alive and well. 


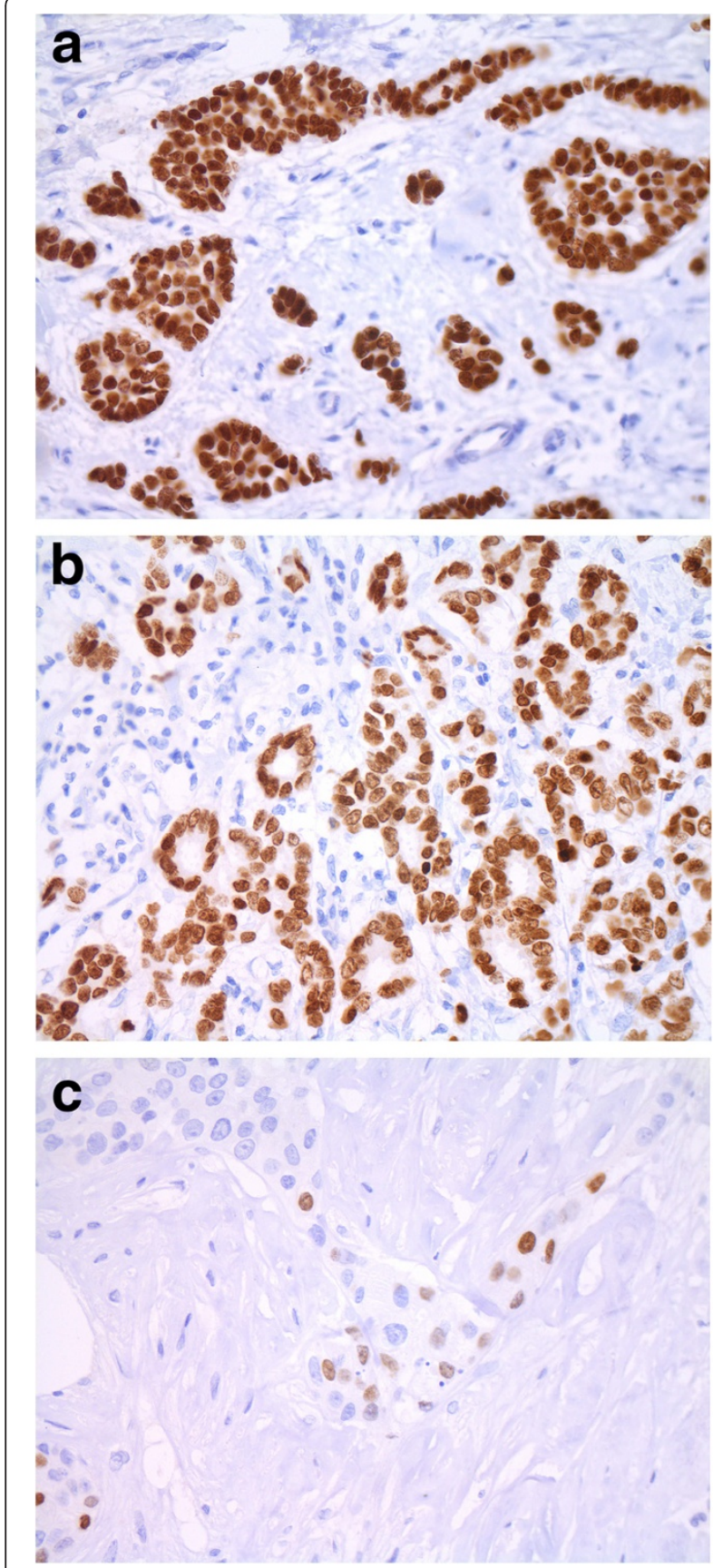

Figure 1 Breast carcinomas with strong $(a, b)$ or weak (c) nuclear expression of TTF1 (x400).

metastasis was unlikely because of the presence of ductal carcinoma in situ and the fact that the patient survived more than 5 years after diagnosis. Third, one of the cases (case \#6) showed typical features of lobular carcinoma, which argues against pulmonary origin.

It can be challenging to differentiate a primary breast carcinoma from a cancer metastasis. Pulmonary adenocarcinomas often demonstrate the same cytokeratin-profile as breast carcinomas with CK7 positivity and CK20

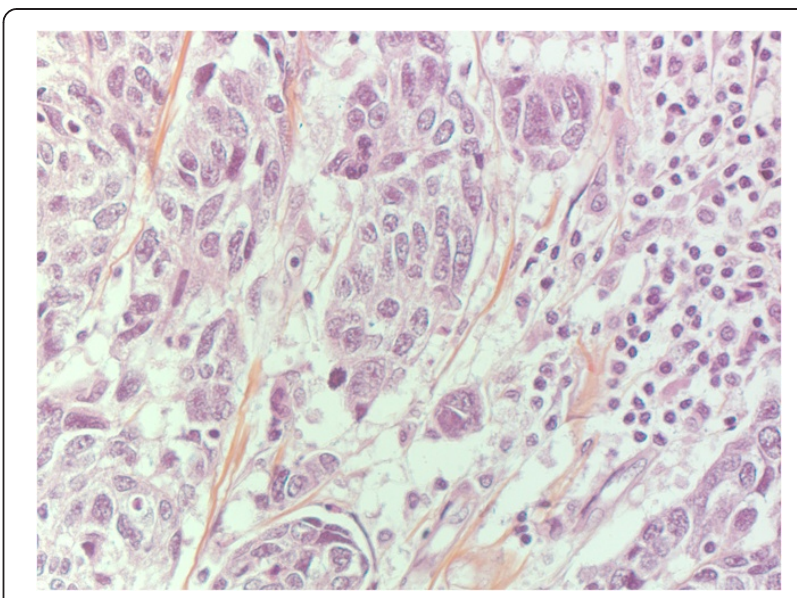

Figure 2 Basal-like morphology with marked nuclear pleomorphism and lymphocytic infiltration in one TTF-1 positive breast carcinoma.

negativity. Also, pulmonary carcinomas can occasionally stain positive for ER, PR, mammaglobin or gross cystic disease protein [7,29-32]. Napsin A is a sensitive marker for lung adenocarcinoma [33], and a combination of TTF1 and Napsin A may possibly be better than TTF-1 alone in confirming or excluding lung metastases to the breast. It is important that several markers are used in combination as a profile to differentiate between breast carcinomas and a metastatic lesion. Clinical and radiological information is also important in achieving the correct diagnosis. Information about known pulmonary tumors should always be included on the pathology request form as well as radiological information pertaining to breast lesions, such as morphology of the tumor and its distance from the skin, which can all be of valuable help in the diagnosis.

In conclusion, our population-based study indicates that TTF-1 expression may be present in $3 \%$ of primary breast cancers. In addition to previous observations, our novel findings indicate that TTF-1 expression is strongly associated with features of aggressive breast cancer and adverse prognostic factors, such as estrogen negativity, increased tumor cell proliferation, a basallike phenotype, blood vessel invasion and lymph node positivity.

\section{Competing interests}

The authors declare that they have no competing interests.

\section{Authors' contributions}

TK wrote the manuscript and participated in the histological evaluation. YC and PS participated in the histological evaluation and writing. IS participated in statistical analysis and writing. MG supplied the relevant radiological details and participated in writing. LAA participated in histological evaluation and writing of the manuscript. All authors read and approved the final manuscript. 


\section{Acknowledgements}

We thank Mrs. Gerd Lillian Hallseth, Mr. Bendik Nordanger, Mrs. Hege Elisabeth Jørgensen and Mrs. Marianne Odnakk Ludahl for excellent technical assistance.

\section{Author details}

${ }^{1}$ Department of Pathology, Vestfold Hospital Trust, Tønsberg, Norway. 2Department of Radiology, Vestfold Hospital Trust, Tønsberg, Norway. ${ }^{3}$ Centre for Cancer Biomarkers, The Gade Institute, University of Bergen, Bergen, Norway. ${ }^{4}$ Department of Pathology, Haukeland University Hospital, Bergen, Norway.

Received: 12 March 2013 Accepted: 28 April 2013

Published: 15 May 2013

\section{References}

1. Berghmans T, Paesmans M, Mascaux C, Martin B, Meert AP, Haller A, et al: Thyroid transcription factor 1 -a new prognostic factor in lung cancer: a meta-analysis. Ann Oncol 2006, 17(11):1673-1676.

2. Ordonez NG: Thyroid transcription factor-1 is a marker of lung and thyroid carcinomas. Adv Anat Pathol 2000, 7(2):123-127.

3. Wong NA, Kamel $H$, Sheffield EA, Sohail M: Positive immunostaining for thyroid transcription factor- 1 in colorectal adenocarcinoma using the 8G7G3/1 monoclonal antibody. J Clin Pathol 2008, 61(9):1070-1071.

4. Kubba LA, McCluggage WG, Liu J, Malpica A, Euscher ED, Silva EG, et al: Thyroid transcription factor-1 expression in ovarian epithelial neoplasms. Mod Pathol 2008, 21(4):485-490.

5. Siami K, McCluggage WG, Ordonez NG, Euscher ED, Malpica A, Sneige N, et al: Thyroid transcription factor- 1 expression in endometrial and endocervical adenocarcinomas. Am J Surg Pathol 2007, 31(11):1759-1763.

6. Bejarano PA, Baughman RP, Biddinger PW, Miller MA, Fenoglio-Preiser C: al-Kafaji B, et al. Surfactant proteins and thyroid transcription factor-1 in pulmonary and breast carcinomas. Mod Pathol 1996, 9(4):445-452.

7. Robens J, Goldstein L, Gown AM, Schnitt SJ: Thyroid transcription factor-1 expression in breast carcinomas. Am J Surg Pathol 2010, 34(12):1881-1885.

8. Sakurai A, Sakai $Y$, Yatabe $Y$ : Thyroid transcription factor-1 expression in rare cases of mammary ductal carcinoma. Histopathology 2011 59(1):145-148

9. Klingen TA, Chen Y, Gundersen MD, Aas H, Westre B, Sauer T: Thyroid transcription factor-1 positive primary breast cancer: a case report with review of the literature. Diagn Pathol 2010, 5:37.

10. Ersahin C, Bandyopadhyay S, Bhargava R: Thyroid transcription factor-1 and "basal marker"-expressing small cell carcinoma of the breast. Int J Surg Pathol 2009, 17(5):368-372.

11. Christie M, Chin-Lenn L, Watts MM, Tsui AE, Buchanan MR: Primary small cell carcinoma of the breast with TTF-1 and neuroendocrine marker expressing carcinoma in situ. Int J Clin Exp Pathol 2010, 3(6):629-633.

12. Straume $\mathrm{O}$, Akslen LA: Alterations and prognostic significance of $\mathrm{p} 16$ and p53 protein expression in subgroups of cutaneous melanoma. Int J Cancer 1997, 74(5):535-539.

13. Elston CW, Ellis IO: Pathological prognostic factors in breast cancer. I. The value of histological grade in breast cancer: experience from a large study with long-term follow-up. C. W. Elston \& I. O. Ellis. Histopathology 1991, 19:403-410. Histopathology 2002 Sep:41(3A):151-2, discussion.

14. Mannelqvist M, Stefansson I, Salvesen HB, Akslen LA: Importance of tumour cell invasion in blood and lymphatic vasculature among patients with endometrial carcinoma. Histopathology 2009, 54(2):174-183.

15. Collett K, Stefansson IM, Eide J, Braaten A, Wang H, Eide GE, et al: A basal epithelial phenotype is more frequent in interval breast cancers compared with screen detected tumors. Cancer Epidemiol Biomarkers Prev 2005, 14(5):1108-1112.

16. Bisceglia M, Galliani C, Rosai J: TTF-1 expression in breast carcinoma-the chosen clone matters. Am J Surg Pathol 2011, 35(7):1087-1088.

17. Matoso A, Singh K, Jacob R, Greaves WO, Tavares R, Noble L, et al: Comparison of thyroid transcription factor- 1 expression by 2 monoclona antibodies in pulmonary and nonpulmonary primary tumors. Appl Immunohistochem Mol Morphol 2010, 18(2):142-149.

18. Comperat E, Zhang F, Perrotin C, Molina T, Magdeleinat P, Marmey B, et al: Variable sensitivity and specificity of TTF-1 antibodies in lung metastatic adenocarcinoma of colorectal origin. Mod Pathol 2005, 18(10):1371-1376.
19. Nordiqc. 2012. www.nordiqc.org/Run-33-B12-G2/Assessment/assessment-33TTF1.htm.

20. Perou CM, Sorlie T, Eisen MB, van de Rijn M, Jeffrey SS, Rees CA, et al: Molecular portraits of human breast tumours. Nature 2000, 406(6797):747-752

21. Reis-Filho JS, Tutt AN: Triple negative tumours: a critical review. Histopathology 2008, 52(1):108-118.

22. Cakir A, Gonul II, Uluoglu O: A comprehensive morphological study for basal-like breast carcinomas with comparison to nonbasal-like carcinomas. Diagn Pathol 2012, 7:145.

23. Arnes JB, Brunet JS, Stefansson I, Begin LR, Wong N, Chappuis PO, et al: Placental cadherin and the basal epithelial phenotype of BRCA1-related breast cancer. Clin Cancer Res 2005, 11(11):4003-4011.

24. Nielsen TO, Hsu FD, Jensen K, Cheang M, Karaca G, Hu Z, et al: Immunohistochemical and clinical characterization of the basal-like subtype of invasive breast carcinoma. Clin Cancer Res 2004, 10(16):5367-5374.

25. Hajdu SI, Urban JA: Cancers metastatic to the breast. Cancer 1972, 29(6):1691-1696

26. Georgiannos SN, Chin J, Goode AW, Sheaff M: Secondary neoplasms of the breast: a survey of the 20th Century. Cancer 2001, 92(9):2259-2266.

27. Vergier B, Trojani M, de Mascarel I, Coindre JM, Le Treut A: Metastases to the breast: differential diagnosis from primary breast carcinoma. J Surg Oncol 1991, 48(2):112-116.

28. Klingen TA, Klaasen $H$, Aas $H$, Chen $Y$, Akslen LA: Secondary breast cancer a 5-year population-based study with review of the literature. APMIS 2009, 117(10):762-767

29. Ishibashi H, Suzuki T, Suzuki S, Niikawa H, Lu L, Miki Y, et al: Progesterone receptor in non-small cell lung cancer-a potent prognostic factor and possible target for endocrine therapy. Cancer Res 2005, 65(14):6450-6458.

30. Nose N, Uramoto H, Iwata T, Hanagiri T, Yasumoto K: Expression of estrogen receptor beta predicts a clinical response and longer progression-free survival after treatment with EGFR-TKI for adenocarcinoma of the lung. Lung Cancer 2011, 71(3):350-355

31. Takeda Y, Tsuta K, Shibuki Y, Hoshino T, Tochigi N, Maeshima AM, et al: Analysis of expression patterns of breast cancer-specific markers (mammaglobin and gross cystic disease fluid protein 15) in lung and pleural tumors. Arch Pathol Lab Med 2008, 132(2):239-243.

32. Wang LJ, Greaves WO, Sabo E, Noble L, Tavares R, Ng T, et al: GCDFP-15 positive and TTF-1 negative primary lung neoplasms: a tissue microarray study of 381 primary lung tumors. Appl Immunohistochem Mol Morphol 2009, 17(6):505-511.

33. Ye J, Findeis-Hosey JJ, Yang Q, McMahon LA, Yao JL, Li F, et al: Combination of napsin A and TTF-1 immunohistochemistry helps in differentiating primary lung adenocarcinoma from metastatic carcinoma in the lung. Appl Immunohistochem Mol Morphol 2011, 19(4):313-317.

doi:10.1186/1746-1596-8-80

Cite this article as: Klingen et al:: Expression of thyroid transcription factor-1 is associated with a basal-like phenotype in breast carcinomas. Diagnostic Pathology 2013 8:80.

\section{Submit your next manuscript to BioMed Central and take full advantage of:}

- Convenient online submission

- Thorough peer review

- No space constraints or color figure charges

- Immediate publication on acceptance

- Inclusion in PubMed, CAS, Scopus and Google Scholar

- Research which is freely available for redistribution 